\title{
Comparative Studies on Reduction of Sulphur Content of Heavy Crude Oil Using $\mathrm{KMnO}_{4}+\mathrm{H}_{2} \mathrm{O}_{2} / \mathrm{CH}_{3} \mathrm{COOH}$ and $\mathrm{KMnO}_{4}+\mathrm{H}_{2} \mathrm{O}_{2} / \mathrm{HCOOH}$ Via Oxidative Desulphurization (ODS)
}

\author{
Sayudi Yahaya Haruna ${ }^{1, ~ *, ~ U m a r ~ Z a k i ~ F a r u q ~}{ }^{1}$, Aminu Yakubu Zubairu ${ }^{1,2}$, \\ Muhammad Gidado Liman ${ }^{1}$, Maryam Lami Riskuwa ${ }^{3}$ \\ ${ }^{1}$ Department of Pure and Applied Chemistry, Usmanu Danfodiyo University, Sokoto, Nigeria \\ ${ }^{2}$ Department of Science Laboratory Technology, Umaru Ali Shinkafi Polytechnic, Sokoto, Nigeria \\ ${ }^{3}$ Department of Micro Biology, Usmanu Danfodiyo University, Sokoto, Nigeria
}

Email address:

sayud7494@gmail.com (S. Y. Haruna)

${ }^{*}$ Corresponding author

To cite this article:

Sayudi Yahaya Haruna, Umar Zaki Faruq, Aminu Yakubu Zubairu, Muhammad Gidado Liman, Maryam Lami Riskuwa. Comparative Studies on Reduction of Sulphur Content of Heavy Crude Oil Using $\mathrm{KMnO}_{4}+\mathrm{H}_{2} \mathrm{O}_{2} / \mathrm{CH}_{3} \mathrm{COOH}$ and $\mathrm{KMnO}_{4}+\mathrm{H}_{2} \mathrm{O}_{2} / \mathrm{HCOOH}$ Via Oxidative Desulphurization (ODS). American Journal of Applied Chemistry. Vol. 6, No. 1, 2018, pp. 15-24. doi: 10.11648/j.ajac.20180601.13

Received: December 10, 2017; Accepted: December 28, 2017; Published: January 17, 2018

\begin{abstract}
Increase by agency protocols, international organisation regulations, and government regulations in many countries, demand for uncontaminated fuel and the use of more environmentally friendly transportation fuels with minor contents of sulphur compound ( $\mathrm{SOx}$ ) and aromatics compound lead to the search of pre-sulphur. In the present time, the demand for transportation fuels has been increasing in many countries for the past two decades. The study reported the compared oxidation-extraction desulphurization of heavy crude oil using combined oxidants potassium permanganate and hydrogen peroxide $\left(\mathrm{KMnO}_{4}+\mathrm{H}_{2} \mathrm{O}_{2}\right)$ over acetic acid $\left(\mathrm{CH}_{3} \mathrm{COOH}\right)$ and Formic acid $(\mathrm{HCOOH})$ catalysis. The following results were obtained; formic acid $(\mathrm{HCOOH})$ with higher sulphur reduction by $(73.00 \%)$, while acetic acid $\left(\mathrm{CH}_{3} \mathrm{COOH}\right)$ with lower sulphur reduction by $(27.02 \%)$. The study concluded that combined oxidants $\left(\mathrm{KMnO}_{4}+\mathrm{H}_{2} \mathrm{O}_{2}\right)$ with formic acid (HCOOH) catalysed reaction system is better than using combined oxidants $\left(\mathrm{KMnO}_{4}+\mathrm{H}_{2} \mathrm{O}_{2}\right)$ with acetic $\mathrm{CH}_{3} \mathrm{COOH}$ catalyst. Moreover DMSO was found to be a pathetic and inadequate solvent for extraction of oxidized sulphur since, it present more sulphur into the oxidised oil higher than that up fresh sample.
\end{abstract}

Keywords: Acetic Acid, Formic Acid, Heavy Crude Oil, ODS, Mix Oxidants $\left(\mathrm{KMnO}_{4}+\mathrm{H}_{2} \mathrm{O}_{2}\right)$

\section{Introduction}

In recent time clean fuels research such as desulfurization, oxidative desulphurization and dearomatization has become one of the essential focus of environmental catalysis studies globally [1].

The level of sulphur content is one of the major essential factors of crude oils marketing price. Nowadays there are different kinds of sulphur compounds in crude oil that can be further divided into four categories for examples: disulfides, mercaptanes, sulfides, and thiophenes, moreover, Sulphur compounds in the refining process are unwanted due to their capability of leading to deactivation of the catalyst and also causes environmental pollution [2].

Heavy crude oil exploitation is a remarkable topic dealing with the scarcity of energy in the globe. Heavy crude oil reservoirs are abundant in the world, they account for $70 \%$ of the total quantity of petroleum. Heavy crude oil contain mainly hydrocarbon with little amount of heteroatoms such as sulphur $(\mathrm{O})$, oxygen $(\mathrm{O})$ and nitrogen $(\mathrm{N})$ compounds, present of sulphur compound in the heavy oil molecules has become the challenges of many refinery and petroleum industry during the exploitation as well as during refine processing. Hence, several techniques such as thermal 
recovery, chemical recovery, microbial recovery, Toe to Heel Air Injection (THAI), Steam Assisted Gravity Drainage (SAGD), in-situ combustion and cyclic steam stimulation (CSS) etc., have been developed and adopted for heavy crude oil derailing [3].

Sulphur content is among the major important characteristics of the crude oil and natural gas due to their high effect to environment as well as affecting human health, and it also devalue quality of the crude oil fraction when found in excess. Nowadays, there is a negative trend of increase of sulphur content in hydrocarbons worldwide, many nations of the world are moving towards environmentally friendly alternative transportation fuels. New transportation fuel policies are being put into consideration worldwide. As a result of those contra guiding factors, such as hydrocarbon quality and reducing the maximum allowable level of sulphur occurrence making the condition bad [4].

Sulphur has been known to be among the major impurity affecting the quality of the final refined product and as well, contributes to high cost dispensation, additionally sulphur compounds in the crude oil generates many operational problems, as well lead to environment pollution when refine product are used by internal combustion engine, the smoke were released to air which lead to air pollution. Sulphur content in petroleum destroys the catalyst by affecting catalyst to be came inactivation [5].

Higher sulphur content in petroleum products contributes to large emissions of sulphur dioxides $\left(\mathrm{SO}_{2}\right)$ and as a result produce acid rain to the environment, as well as providing poor performance of vehicle emissions control systems. Refining instruments across corrosion problems when handling heavy crude oil with huge amount of high sulphur compounds, besides, sulphur compounds are extremely unwanted in commercial products due to their nasty smell or ruthless odour [6].

The occurrence of sulphur has an implication effect on the price of the crude oils, due to its adverse environmental consequence as well as the outcome of end refined products, thus led to severe environmental protocols passing large regulations on refinery operatives globally to decrease sulphur contents of crude oil products [7]. In the previous era many strict laws on the standard and benchmark of sulphur level in fusel fuels have been introduced in many countries, nowadays the production of ultra-low sulphur fuel has become an essential mission of refines industries [8].

Generally crude oils has unrelated quantities and forms of sulphur compounds, however as a guideline the quantity, stability, and complexity of the compounds are much higher in heavy crude oil fractions [5].

When petroleum products comprise up sulphur compounds undergo combustion, may produces undesirables compound like sulphuric acid $\left(\mathrm{H}_{2} \mathrm{SO}_{4}\right)$ and sulphur dioxide $\left(\mathrm{SO}_{2}\right)$, many refineries implemented hydro-treating processes or hydrodesulphurization (HDS) reaction which includes catalytic alteration of many sulphur compounds to nonsulphur no-inclusive materials at the occurrence of hydrogen, however some amount of sulphur remain in the products, thus another methods with simple operating conditions is also needed as well as the practice of dynamic catalyst and imaginable advanced technologies were also required [9]. In current time, many research has try to discover advance and cheapest process that could replace hydro-treating in other to reduce the cost of production, as well to reduce the level of sulphur. One of the alternative that have the golds of meeting the demand was oxidative desulphurization by using organic or inorganic peroxide as oxidants in the present of ideal catalyst [6]. It is recognised that reacting a petroleum fuels with an oxidant alters the organo-sulphur and nitrogen compounds present in fuels to sulphones compound (or sulphoxides compound) as well as organic nitric oxides. These polar organic oxides can be separated from the fuels by solvent extraction and/or by adsorption. Moreover, oxidative desulphurization can simply oxidize and remove thiophenic sulphur compounds, which cannot be remove by HDS due to the stereo hindrance (interference) effect within the sulphur atom in the molecule [5].

For instance, it has been testified that the action of thiophenic compounds in reacting to HDS treatment occur in this order: DBT (dibenzothiophene) > 4-MDBT (4-methyl dibenzothiophene) $>4,6$ DMDBT (4, 6-dimethyl dibenzothiophene). Additionally, it has been testified that the activity of thiophenic compounds in responding to oxidative treatment is just the reverse, for example: 4, 6-DMDBT $>4$ MDBT $>$ DBT. These interpretations advise that oxidative desulphurization can be active in eliminating the most challenging residual sulphur compounds from hydrotreated oils to produce ultra-low sulphur products [8]. Although, the oxidants used in the oxidative desulphurization process can be active in aqueous intermediate or in non-aqueous intermediate. It has been recognised that via aqueous oxidant involves a phase transfer agent (catalyst) to carry out the oxidant from the aqueous phase to the oil phase where it reacts the organosulphur compounds, beside one of the problem related with the use of aqueous oxidants is the precipitation of important portion of the sulphones from the liquid phases which disturb the process [10].

Crude oil is a complex mixture comprised of thousands number of hydrocarbons compound (C-C bond), nonhydrocarbon compounds ( $\mathrm{S}, \mathrm{N}, \mathrm{O}$, etc.) as well as heavy metals $(\mathrm{Pb}, \mathrm{Cu}, \mathrm{Ca}$, etc.). Or crude oils are flammable liquid recognised to contain mainly hydrocarbons mixed with little amount of sulphur-, nitrogen-, and oxygenated compounds [11].

Heavy metals are in the forms of inorganic salts or organometallic compounds like porphyrinate complexes ware present in the complex mixture of crude oil in small quantities, it is forecast that crude oil will be existing as a source of energy for many decades to subsequent era, on the other hand, there has been additional needs for crude oil quality disintegration as the left behind contents of the recognised reservoirs tend to be of substantial and sourer composition and new wells are rarely to be across [12].

By the increase awareness that oil is a limited resource, it 
is well essential to try to use it as efficiently as potential by controlling its environmental impact by processing productivity, by reducing sulphur content in different fuels. Moreover many strict laws to reduce levels of sulphur content in fuels have been offered by environmental regulating agencies in many countries of the world, all pointing toward limiting levels of sulphur content in crude fractions to was ultra-low level between $10-15 \mathrm{ppm}$ by 2015 [9-12].

Many criteria have been used to categorise crude oils; which are differences in form and viscosity of oils from one oil reservoir to another as well as chemical composition present, these differences in form are range in aroma and colour, but the viscosity and gravity of the crude can be classified based on American Petroleum Institute (API) gravity and viscosity. For instance, if the API gravity of the crude oil is between 0-20 degrees are placed as heavy crude oil, while those above API gravity $\geq 40.1$ degrees are placed as light crude oil and if the oil fall between 20 and 40.1 degrees was categorised as medium crude oil (intermediate crude) [13].

Classifications may be based on chemical properties present in the crude, for instance, vanadium-to-nickel ratio (V: Ni), nitrogen and sulphur content $(\mathrm{N}, \mathrm{S})$. It is identified that crude oil with low content of sulphur is call sweet, but crude with high presence sulphur content is call (sour), respectively every crude oil poses different compound, composition or properties that is not correspond with other sample of crude, moreover chemical and physical composition of crude oil vary not only with the site and oldness of the oil field, but also varies with the depth of the different well, besides, two neighbouring oil reservoirs may produce hydrocarbons with different properties [14].

In order to know the behaviour of sulphur compounds present in crude oil the basic knowledge of all crude oil composition were required. The major compound found in crude oils are hydrocarbons mostly $\left(\mathrm{C}_{1}\right.$ to $\left.\mathrm{C}_{6}\right)$. The hydrocarbon content may be much as $97 \%$ by weight in light paraffinic oils or lower as $50 \%$ by weight in heavy crude oil and bitumen, other non-hydrocarbon compound include small amount of organic compounds such as sulphur (S), oxygen $(\mathrm{O})$, and nitrogen $(\mathrm{N})$, as well as compounds with metallic elements like vanadium $(\mathrm{V})$, nickel $(\mathrm{Ni})$, iron $(\mathrm{Fe})$, and copper $(\mathrm{Cu})[15]$.

Crude oils contain some extents of organic non-hydrocarbon elements, those elements exist in organic compounds, such as hetero-atoms (carbon and hydrogen atoms) with either sulphur, nitrogen, and oxygen compounds present in the ring, with high boiling point, but tend to distillate mostly in the heavier fractions [16]. Even though they are little constituents of crude oil, their increased processing or operation costs, most of the sulphur and nitrogen compounds increasing high operational cost to crude oil refiners and petrochemical industries. Fuels with higher sulphur, if burned by combustion engine in vehicles or power plants, also pollute the environment, beside lead to acid rain. For several refining processes, sulphur is a promoter poison likewise nitrogen is also promoter of poison, thus, refiners offer a large quantity of time and money to eliminate heteroatoms from intermediate streams and finished products [17].<smiles>CCCSC</smiles>

methy propyl sulfide

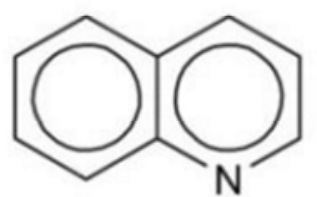

quinoline<smiles>CC1CCCSC1</smiles>

3-methylthiacyclohexane

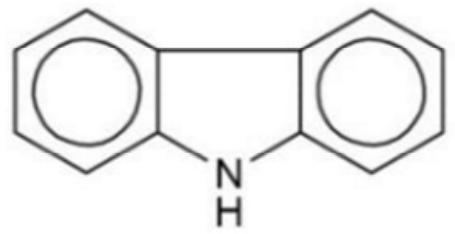

carbazole

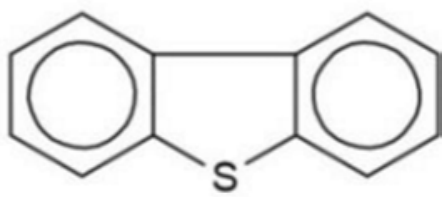

dibenzothiophene

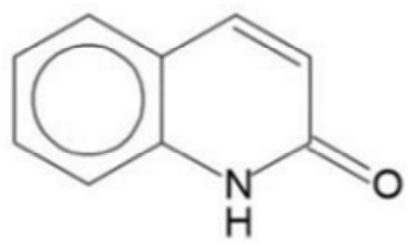

$2(1 H)$ quinolin-one

Figure 1. Hetero-atom compounds found in crude oil [17].

In the substantial fractions such as resins and asphaltenes organometallic compounds like nickel (Ni) and vanadium (V) are originate and their concentrations have to be condensed by altering the oil to transportation fuel form. The concentration of metal compounds ranges between little ppm to $200 \mathrm{ppm}$ for nickel (Ni) and up to $1200 \mathrm{ppm}$ for vanadium (V) [17]. 


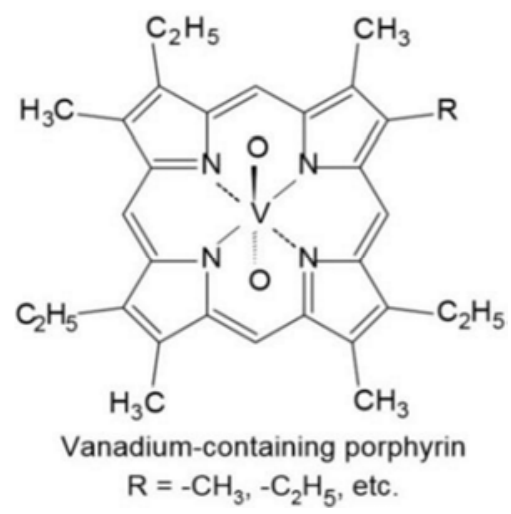

Figure 2. Organometallic compounds found in crude oil [17].

Hydrodesulphurization (HDS) also refers as hydro-treating process, is one of the well-known desulfurization methods that have been run by refinery processes since the 1950s, hydrodesulphurization (HDS) can be achieved by using fixed bed reactor [18]. The sulphur bearing hydrocarbon feed (heavy crude oil) and hydrogen gas are past to the reactor, the sulphur bearing hydrocarbon feed are pump and high pressurised between the range 13 to 130 atmospheres. The high pressurised feed are link with hydrogen gas and then pass over heat exchanger to heat up the liquid-gas mixture at temperatures ranging between 300 to $400^{\circ} \mathrm{C}$, in the reactor, catalyst cobalt and molybdenum over alumina $\left(\mathrm{CoMO} / \mathrm{Al}_{2} \mathrm{O}_{3}\right)$ base are used to enhance (speed) the reaction which convert organic sulphur compounds (OSCs) to hydrogen sulphide [19].

Besides mixture of hydrocarbons, hydrogen gas and hydrogen sulphide in the reactor were further pass through gas separator in order to separate the fuel from hydrogen gas and hydrogen sulphide, the separated phases of hydrogen and hydrogen sulphide are treated with amine gas in order to purify hydrogen gas for recycling in the reactor and hydrogen sulphide are oxidized to sulphur dioxide $\left(\mathrm{SO}_{2}\right)$ by air, and sulphur is formed, the process is known as Claus process, the overall reaction is show below [20].

$$
2 \mathrm{H}_{2} \mathrm{~S}+\mathrm{SO}_{2} \rightarrow 3 \mathrm{~S}(\mathrm{~s})+2 \mathrm{H}_{2} \mathrm{O}
$$

Fuel produced from the gas separator are further treated in stripper distillation unit with reflux in an attempt to remove gases such as hydrogen $(\mathrm{H})$, hydrogen sulphide (HS), methane $\left(\mathrm{CH}_{4}\right)$, ethane $\left(\mathrm{CH}_{3} \mathrm{CH}_{3}\right)$, propane $\left(\mathrm{CH}_{3} \mathrm{CH}_{2} \mathrm{CH}_{3}\right)$ and other volatile organic compounds, In the same way, the gas mixture are treated with amine gas to recover hydrogen sulphide, the residual fraction may be utilised for other purposes like refinery fuel gas [3].

Even though hydrodesulphurization (HDS) has been utilised to synthesed low sulphur fuel for years, the approaching tautened regulations will be the big challenge on this process, even do hydrodesulphurization (HDS) was recognised to desulfurize mercaptans, sulphides and thiophene, Still, the more condensed by-products are benzothiophenes (BTs) and dibenzothiophenes (DBTs) are major challenging compound to eradicate by hydrodesulphurization (HDS), it is well-known that reactivity of the one- to three-ring organic sulphur compounds (OSCs) reduce by Thiophenes > Benzothiophenes > Dibenzothiophenes [21].

It is reported that low sulphur diesel fuel produced by hydrodesulphurization (HDS) contains approximately $500 \mathrm{ppm}_{\mathrm{w}}$ of sulphur, mostly alkyl derivatives of DBTs which are considered as refractory compounds and cannot be easily desulfurized through hydrodesulphurization (HDS) [22].

Moreover 4-alkyl DBTs, 6-alkyl DBTs and 4, 6-alkyl DBTs have very low reactivity which can be illuminated by mixtures of electronic density, bond order, and spatial, geometric and steric interference around the sulphur atom [23]. 4, 6-dimethyl-dibenzothiophenes are familiar for its high stability against hydrodesulphurization (HDS). Therefore, traditional hydrodesulphurization (HDS) is not applicable to produce ULSD needed by new sulphur regulations [24]. The structure of 4, 6-DMDBT is shows in figure 3 .

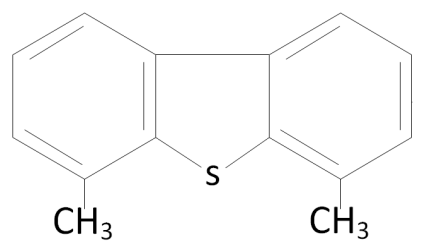

Figure 3. structure of 4, 6-DMDBT [24].

Adjustments on hydrodesulphurization (HDS), including increase of hydrogen, catalyst quantity, and as well as operating pressure, have been studied, overall, hydrogen usage is the main operational cost of hydrodesulphurization (HDS), as to reduce the sulphur content from $500 \mathrm{ppm}_{\mathrm{w}}$ to $15 \mathrm{ppm}_{\mathrm{w}}$, an increase of $25 \%$ to $45 \%$ of hydrogen gas is needed [25]. This indicates that the operational cost will be doubled up, then again, doubling catalyst quantity can only lower the sulphur content by $100 \mathrm{ppm}_{\mathrm{w}}$, and hence, an affected increase in catalyst dosage is also necessary to produce ULSD [26].

As proposed by the National Petroleum Council, operating pressure has to be improved from 1100psi to 1200 psi so as to produce diesel with low than $30 \mathrm{ppm}_{\mathrm{w}}$ sulphur, thus this needs a specific thick-walled reactor to withstand with high pressure, and as a result increasing the investment and operational costs, also the massive increase in cost, safety issue is also a big problems for hydrodesulphurization (HDS) which involves high operating temperature and pressure with the use of hydrogen gas, moreover reactor failure as well as explosion can be occurred if uncontrollable (hot-spots) phenomenon, or any other operation errors will happen [27].

Nowadays petroleum industry begin to give new attention to the advance of cost operational alternatives as a replacement of depended totally traditional hydro-treating operation, oxidative desulfurization is among the best substitute methods proposed, although research on developing industrial futures golds of this method was initiated in the 1990s [28].

Oxidative desulfurization (ODS) is deliberated as the upto-date alternative desulfurization process which consist of 
chemical oxidation of divalent organic sulphur compounds to the equivalent hexavalent sulphur, also well-known as sulphone, those physical and chemical properties of sulphones, are boiling points, polarity and solubility in different solvents, and are entirely diverse from the original sulphur compounds, generally, sulphones poses higher boiling points and improved polarity which leads to higher solubility [29].

Ideally, oxidation desulphurization (ODS) can be accomplished by many type of oxidants such as nitric acid catalyst and nitrogen oxides were among the common oxidants used to remove both organic sulphur compounds and organic nitrogen compounds in nineteen century, because of the poor selectivity, low yield and loss in heating value for the treated heavy crude oil, these oxidants have not been usually used today [30].

Even though oxidative desulfurization can be achieved by noncatalytic oxidation or catalytic oxidation of OSCs, noncatalytic oxidative desulfurization processes involves high temperature of about $200^{\circ} \mathrm{C}$ and high pressure [31].

When compare, catalytic oxidative desulfurization needs moderately slight environments at temperature between $25^{\circ} \mathrm{C}$ to less than $100^{\circ} \mathrm{C}$ under ambient pressure. Different types of ODS catalysis such as aldehydes [32], transition metal salts [33], polyoxometalate acids [34] and carboxylic acids, but organic acids -and polyoxometalate acids are the major ones generally used [22].

This research work was aimed at reducing the sulphur content of heavy crude oil prior to processing using combination of two alternative oxidants for the oxidative desulphurization process potassium permanganate and hydrogen peroxide $\left(\mathrm{KMnO}_{4} / \mathrm{H}_{2} \mathrm{O}_{2}\right)$ as oxidants over formic acid and acetic acid as a catalyst for oxidative desulphurization (ODS) of heavy crude oil, and then solvent extraction with DMSO.

The objectives of the research are summarised below:

i. To compare the effect of mix oxidants; potassium permanganate and hydrogen peroxide $\left(\mathrm{KMnO}_{4} / \mathrm{H}_{2} \mathrm{O}_{2}\right)$ on oxidative desulphurization.

ii. To examine the effect of two acid catalysts; acetic acid and formic acid, on oxidative desulphurization as well as to compare their efficiency in reducing the sulphur content present in heavy crude oil.

iii. To study the effects of reactions temperature at $60^{\circ} \mathrm{C}$ on the efficiency of desulphurization of the heavy oil.

iv. To measure the amount of sulphur content of the untreated and desulphurized crude sample.

$v$. To investigate the effect of the oxidation-extraction system on the oil quality and distribution of the sulphur compounds

\section{Material and Method}

\subsection{Sample Collection}

The heavy crude oil (sulphur content, $1.1934 \mathrm{wt} \%$ ) was collected from Fluid Laboratory unit, Operation Department
(OPS) of Kaduna Refining and Petrochemicals Company (KRPC) Kachia Road Kaduna State, Niigeria. conventional laboratory reagents, apparatus and some equipment were also used.

\subsection{Reagents and Materials}

The reagent and instruments used in this research were: Acetic Acid $\left(\mathrm{CH}_{3} \mathrm{COOH}\right)$, potassium permanganate $\left(\mathrm{KMnO}_{4}\right)$, Hydrogen Peroxide $\left(\mathrm{H}_{2} \mathrm{O}_{2}\right)$, De-ionize water, Formic acid (HCOOH), Dimethylsulphoxide (DMSO), Model SLFA-60 X-ray fluorescence sulphur-in-oil analyser, Cary 630 model FTIR spectrometer, Thermometer, $250 \mathrm{~cm}^{3}$ conical flask and Separating funnel.

\subsection{Preparation of Catalyst}

This was prepared by dissolving 197.5375 of $\mathrm{KMnO}_{4}$ in $150 \mathrm{~cm}^{3}$ of de-ionize water and the solution was made to the mark with the same de-ionized water in a $250 \mathrm{~cm}^{3}$ volumetric flask. The solution did not dissolved completely, hence it was used as saturated solution [35].

\subsection{Oxidative Desulphurization}

\subsubsection{Oxidation of Crude Oil Using ( $\mathrm{KMnO}_{4}+\mathrm{H}_{2} \mathrm{O}_{2}$ $\mathrm{HCOOH)}$}

The oxidation of crude oil was conducted in a flask with electrical stirrer. Precisely, $15 \mathrm{~cm}^{3}$ of crude oil sample was poured into $250 \mathrm{~cm}^{3}$ conical flask and mixed with $5 \mathrm{~cm}^{3}$ of acetic acid (catalyst), followed by $5 \mathrm{~cm}^{3}$ of $\mathrm{H}_{2} \mathrm{O}_{2}$. A thermometer was inserted and the flask was placed on the heating mantle with magnetic bar stirring at 750 rpm. Consequently the mixture was heated to $60^{\circ} \mathrm{C}$, and $5 \mathrm{~cm}^{3}$ of saturated solution of potassium permanganate was added in drop wise and with constant stirring over 15 minutes to oxidize sulphur compounds in the sample. The content was transfer in to separating funnel allowed to stand for 2 hours and oil phase was separated and labelled as "Oxidized oil A" (A). The procedure was repeated three times in order to obtain the average. The mixture was analysed by XRF in order to determine the sulphur content.

\subsubsection{Oxidation of Crude Oil Using $\left(\mathrm{KMnO}_{4}+\mathrm{H}_{2} \mathrm{O}_{2} / \mathrm{CH}_{3} \mathrm{COOH}\right)$}

The oxidation of crude oil was conducted in a flask with electrical stirrer. Precisely, $15 \mathrm{~cm}^{3}$ of crude oil sample was poured into $250 \mathrm{~cm}^{3}$ conical flask and mixed with $5 \mathrm{~cm}^{3}$ of formic acid (catalyst), followed by $5 \mathrm{~cm}^{3}$ of $\mathrm{H}_{2} \mathrm{O}_{2}$. A thermometer was inserted and the flask was placed on the heating mantle with magnetic bar stirring at 750rpm. Consequently the mixture was heated to $60^{\circ} \mathrm{C}$, and $5 \mathrm{~cm}^{3}$ of saturated solution of potassium permanganate was added in drop wise and with constant stirring over 15 minutes to oxidize sulphur compounds in the sample. The content was transfer in to separating funnel allowed to stand for 2 hours and oil phase was separated and labelled as "Oxidized oil B" (B). The procedure was repeated three times in order to obtain the average. The mixture was analysed by XRF in 
order to determine the sulphur content.

\subsection{Extraction of Oxidized Oil}

The extraction of oxidized sulphur compounds from the recovered oil were conducted with Dimethylsulphoxide (DMSO). $10 \mathrm{~cm}^{3}$ of DMSO was added to $10 \mathrm{~cm}^{3}$ of the oxidized oil in a $250 \mathrm{~cm}^{3}$ separating funnel, shaken for five minutes and left for two hours for two-phase separation. The crude oil phase was separated carefully from the DMSO phase and levelled as "DMSO Extracted" (DE) followed by the lettered number and the reaction temperature. The acetic $\left(\mathrm{KMnO}_{4}+\mathrm{H}_{2} \mathrm{O}_{2}\right)$ at $60^{\circ} \mathrm{C}$ was levelled $\mathrm{DEA}_{60}$, that formic acid $\left(\mathrm{KMnO}_{4}+\mathrm{H}_{2} \mathrm{O}_{2}\right)$ as $\mathrm{DEB}_{60}$.

\subsection{Determination of Total Sulphur Content}

The total sulphur content was determined using X-ray fluorescence sulphur-in-oil analyser SLFA-60 in accordance with the ASTM-D1552 requirement. The sample was poured into a disposable sample container to three quarter of its capacity. This is to ensure the $\mathrm{X}$ - ray passes through the test sample in order to give accurate sulphur counts. The sample was then covered with $\mathrm{X}$ - ray transparent plastic film window. The power was switched on and light up the X- ray lamp within seconds. The analyser gives three different readings at 30 seconds intervals. The readings were recorded and average sulphur content was determined in percentage sulphur by weight. Same procedure was carried out on the fresh oil sample.

\subsection{FTIR Spectrophotometric Analysis}

The FTIR analysis was conducted at Central Lab Bayaro University Kano (BUK), using Cary model-630 spectrometer. A drop of untreated crude oil sample was placed between two plates of potassium bromide, $\mathrm{KBr}$ cells and squeeze to remove any trapped air in order to form a thin film (sand witched) between the plates otherwise light cannot pass through. The plates were placed in the sample holder and positioned in the standard sample cubicle of the spectrometer and then FT-IR spectra were obtained under 2 minutes data collection period with a spectral range from 4000.00 to $650.00 \mathrm{~cm}^{-1}$ at a resolution of $4 \mathrm{~cm}^{-2}$. The procedure was repeated for oxidized crude oil, oxidized and extracted crude oil. The resulting FTIR spectral pattern is then analysed and matched with known initials of identified materials in the FTIR library.

\section{Results}

The results obtained from various analysis are present in Table 1 to 4

Table 1. The results of the average sulphur contents in oxidized oil using $\mathrm{KMnO}_{4}+\mathrm{H}_{2} \mathrm{O}_{2} / \mathrm{CH}_{3} \mathrm{COOH}$ and $\mathrm{KMnO}_{4}+\mathrm{H}_{2} \mathrm{O}_{2} / \mathrm{HCOOH}$.

\begin{tabular}{llll}
\hline S/N & Sample Identity & Sulphur Content (wt\%) & Sulphur Reduction (\%) \\
\hline 1 & A & $0.8745 \pm 0.0364$ & 29.00 \\
2 & B & $0.3246 \pm 0.0273$ & 73.00 \\
3 & Fresh sample & $1.1934 \pm 0.0017$ & - \\
\hline
\end{tabular}

*Results are means and means standard deviation of three replicate analyses.

Key: $\mathrm{A}=\mathrm{KMnO}_{4}+\mathrm{H}_{2} \mathrm{O}_{2} / \mathrm{CH}_{3} \mathrm{COOH} ; \mathrm{B}=\mathrm{KMnO}_{4}+\mathrm{H}_{2} \mathrm{O}_{2} / \mathrm{HCOOH}$.

Table 2. Results of average sulphur contents in the oxidized oil after extraction with DMSO.

\begin{tabular}{llll}
\hline S/N & Sample Identity & Sulphur Content $(\mathbf{w t} \%)$ & Reduction $(\%)$ \\
\hline 1 & EAA & $7.7661^{*} \pm 0.0114$ & - \\
2 & EAB & $8.1340^{*} \pm 0.4669$ & - \\
3 & Fresh sample & $1.1934 \pm 0.0017$ & \\
\hline
\end{tabular}

*Results are means and means standard deviation of three replicate analyses.

Key: $\mathrm{A}=\mathrm{KMnO}_{4}+\mathrm{H}_{2} \mathrm{O}_{2} / \mathrm{CH}_{3} \mathrm{COOH} ; \mathrm{B}=\mathrm{KMnO}_{4}+\mathrm{H}_{2} \mathrm{O}_{2} / \mathrm{HCOOH}$.

Table 3. Chemical compounds of Sulphur Compounds present in FT-IR Spectrophotometric Analysis of Heavy Crude Oil Sample.

\begin{tabular}{lll}
\hline Possible compound present & Ranges & Comments \\
\hline C-S & $726-550$ & Of aromatic, often weak, broad, strong of variable intensities. \\
R-SO-R & $1060-1015$ & Strong, sometimes multiple bands, weak to medium of variable intensities. \\
$\mathrm{S}=\mathrm{O}$ & $1225-950$ & Strong, sometimes multiple bands, weak to medium of variable intensities. \\
\hline
\end{tabular}

Table 4. The results of FT-IR spectrophotometric analysis of heavy crude Oil sample using $\mathrm{KMnO}_{4}+\mathrm{H}_{2} \mathrm{O}_{2} / \mathrm{CH}_{3} \mathrm{COOH}_{\text {and }} \mathrm{KMnO}_{4}+\mathrm{H}_{2} \mathrm{O}_{2} / \mathrm{HCOOH}$

\begin{tabular}{lllll}
\hline Sample identity & IR- Bands & & & \\
\hline & C-S $\left(\mathbf{c m}^{-1}\right)$ & Intensity $\mathbf{( \% T )}$ & R-SO-R/S=O (cm $\left.\mathbf{~}^{-\mathbf{1}}\right)$ & \\
\hline A & 724 & 80.386 & 1018 & 84.330 \\
B & 724 & 82.081 & 1018 & 95.689 \\
DAE & 724 & 90.634 & 1033 & 96.469 \\
DEB & 724 & 67.724 & 1015 & 69.010 \\
Fresh Sample & 724 & 90.177 & - & - \\
\hline
\end{tabular}

$\mathrm{A}=\mathrm{KMnO}_{4}+\mathrm{H}_{2} \mathrm{O}_{2} / \mathrm{CH}_{3} \mathrm{COOH} ; \mathrm{B}=\mathrm{KMnO}_{4}+\mathrm{H}_{2} \mathrm{O}_{2} / \mathrm{HCOOH} ; \mathrm{DAE}=(\mathrm{DMSO}$ Extracted $) \mathrm{KMnO}_{4}+\mathrm{H}_{2} \mathrm{O}_{2} / \mathrm{CH}_{3} \mathrm{COOH} ;$ and DEB $=(\mathrm{DMSO}$ Extracted $)$ $\mathrm{KMnO}_{4}+\mathrm{H}_{2} \mathrm{O}_{2} / \mathrm{HCOOH}$. 


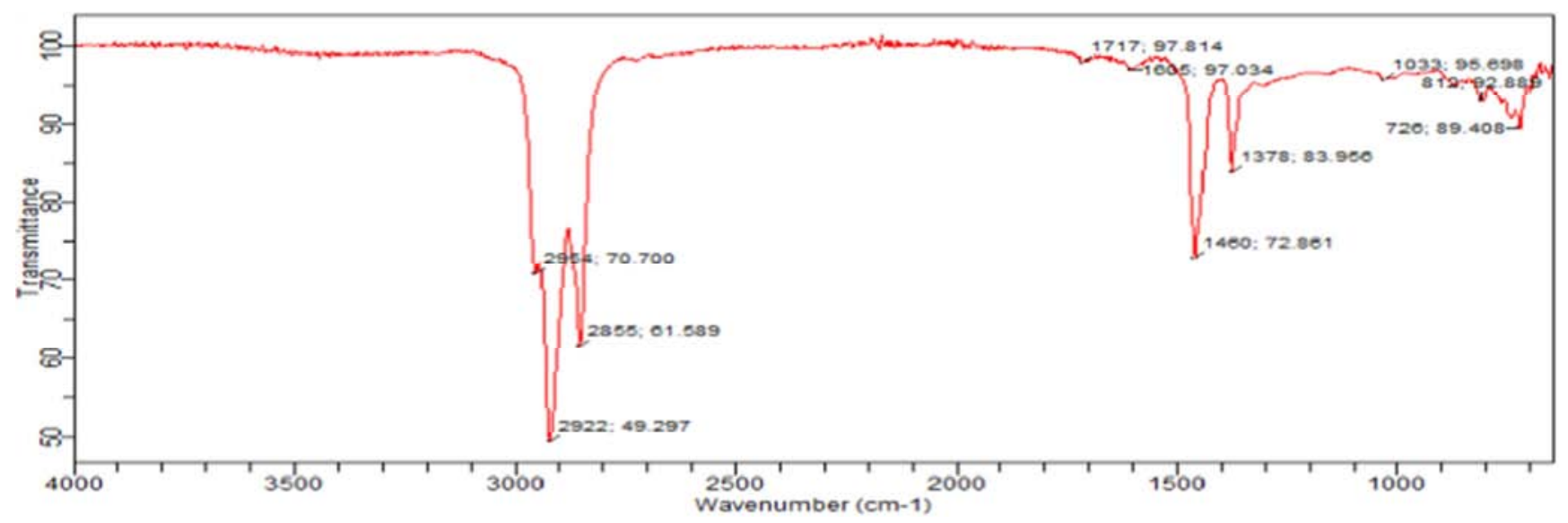

Figure 4. FT-IR spectrophotometric analysis of fresh heavy crude oil.

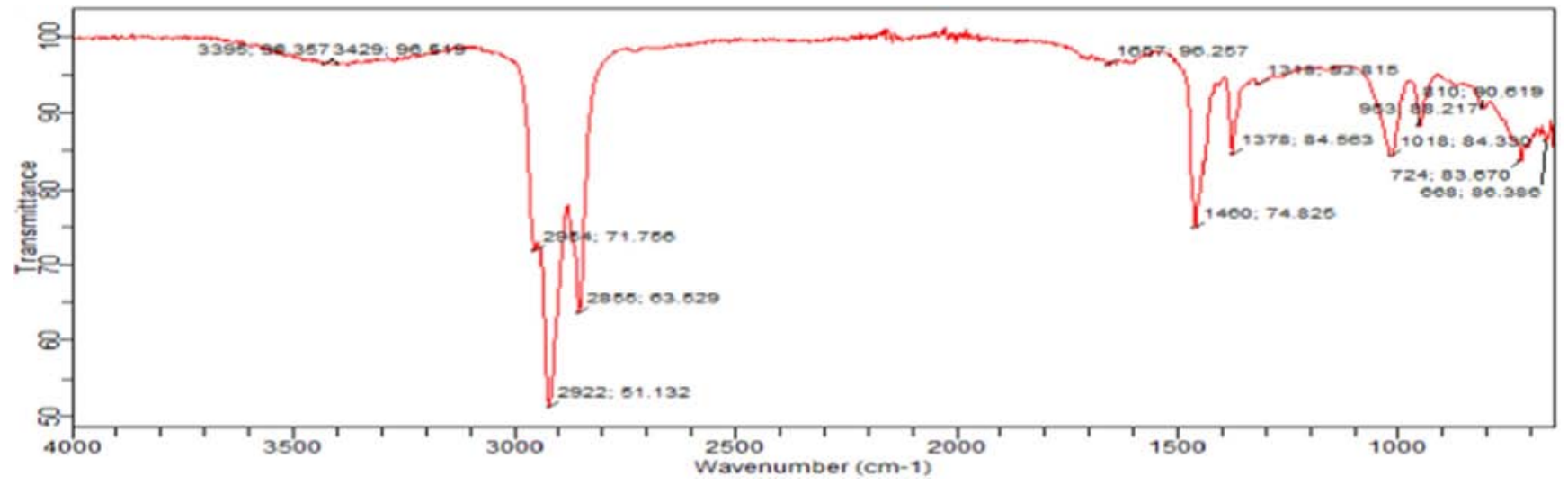

Figure 5. FT-IR spectrophotometric analysis of oxidized oil, using $\mathrm{KM}_{n} \mathrm{O}_{4}+\mathrm{H}_{2} \mathrm{O}_{2} / \mathrm{CH}_{3} \mathrm{COOH}$.

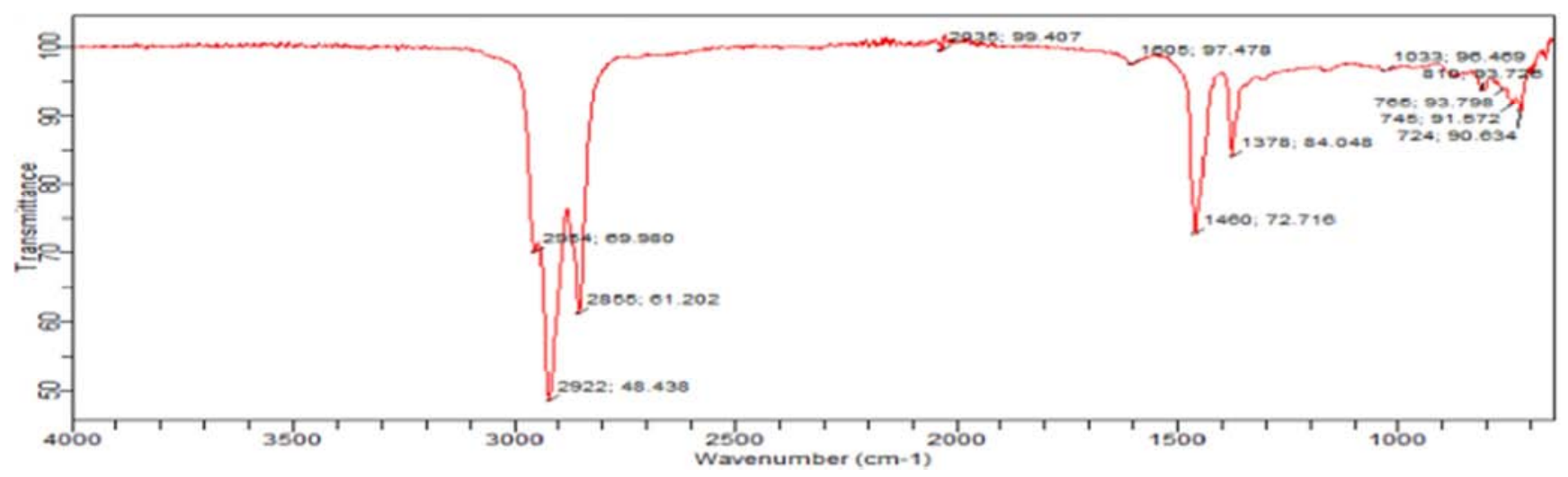

Figure 6. FT-IR spectrophotometric analysis of oxidized oil after extraction, using $\mathrm{KM}_{n} \mathrm{O}_{4}+\mathrm{H}_{2} \mathrm{O}_{2} / \mathrm{CH}_{3} \mathrm{COOH}$.

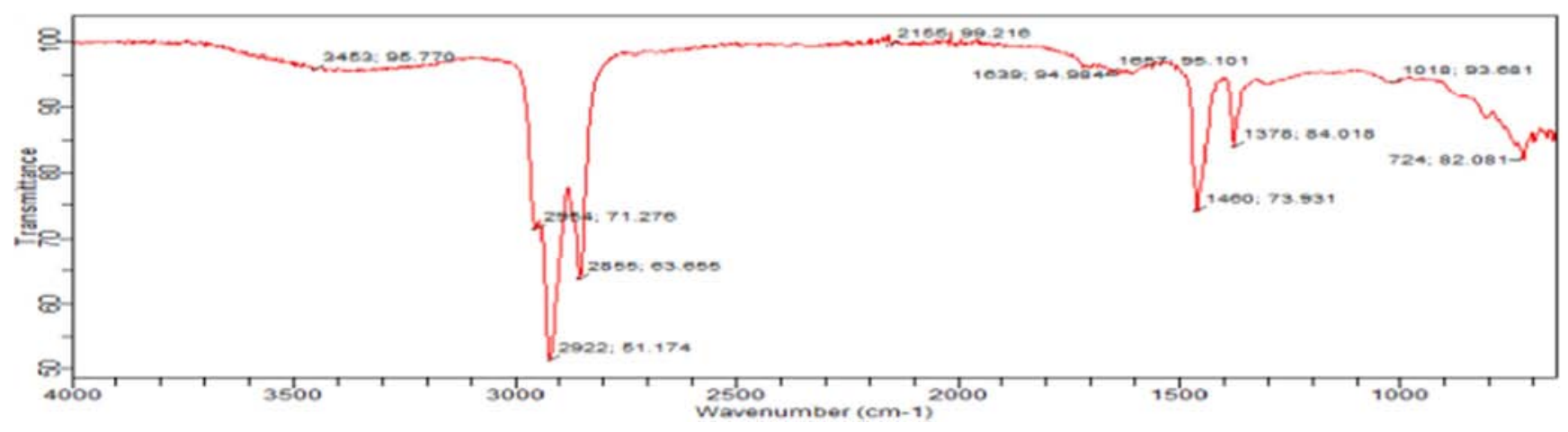

Figure 7. FT-IR spectrophotometric analysis of oxidized oil, using $\mathrm{KM}_{n} \mathrm{O}_{4}+\mathrm{H}_{2} \mathrm{O}_{2} / \mathrm{HCOOH}$. 


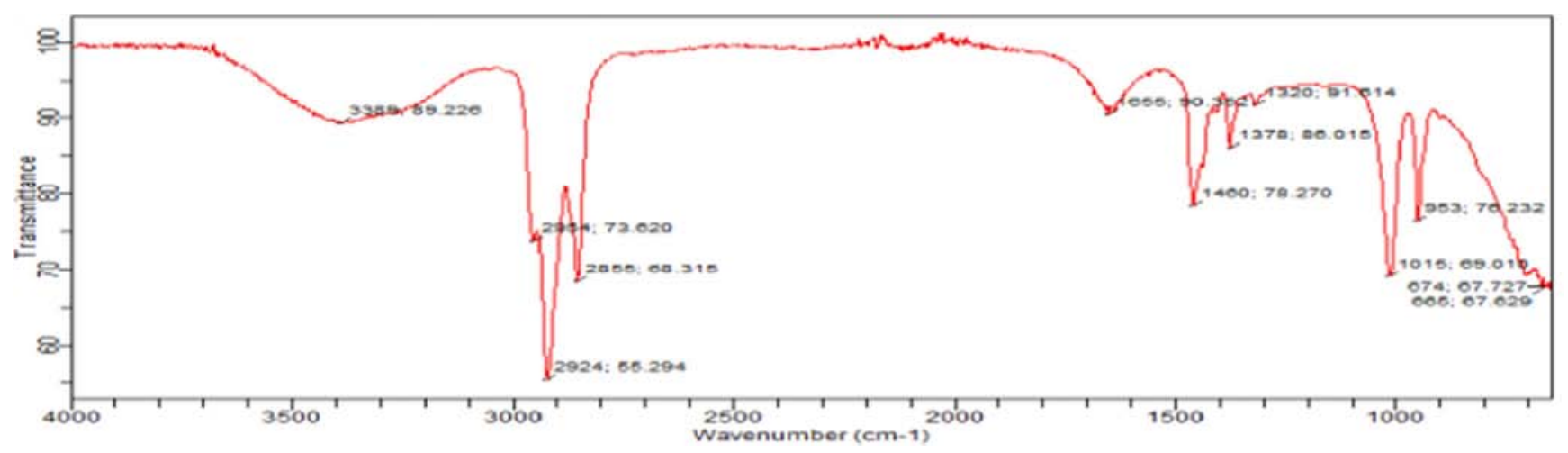

Figure 8. FT-IR spectrophotometric analysis of oxidized oil after extraction, using $\mathrm{KM}_{n} \mathrm{O}_{4}+\mathrm{H}_{2} \mathrm{O}_{2} / \mathrm{HCOOH}$.

\section{Discussion}

As previously point out in the aim of this study, the idea is to oxidized the sulphur compounds in the heavy crude oil in to polar oxygenated compounds so that, they can be extracted out of the oil leaving behind desulphurized oil without using expensive high temperature hydro-treating processes. Thus the oil was treated with aqueous solution of combined oxidants $\mathrm{KMnO}_{4}+\mathrm{H}_{2} \mathrm{O}_{2}$ using acetic acid $\left(\mathrm{CH}_{3} \mathrm{COOH}\right)$ and formic acetic acid $(\mathrm{HCOOH})$ catalysts. The mix reagents is expected to oxidize all organic sulphur to sulphoxide. The sulphoxides so produced were expected to migrate from the oil phase which is largely non-polar phase to the polar aqueous phase. Then, after the reaction, which was continuously stirred to ensure proper contact of the oil with the oxidant, the content was allowed to stand to allow for separation. The oil phase was then analysed for sulphur content in comparison to the fresh sample. However, some of the oxidized sulphur compounds are still expected to remain in the oil phase because, it is expected to distribute itself in to the two phases. Therefore, in order to achieve exhaustive desulphurization, the oxidized oil was extracted with DMSO. The idea of using DMSO is because, it is a sulphur-based solvent which is expected to be an excellent solvent for other sulphoxide compounds thus, removing then quantitatively from the oil.

Table 1: showed the results of the average sulphur content in oxidized and separated oil, using $\mathrm{KMnO}_{4}+\mathrm{H}_{2} \mathrm{O}_{2}$ oxidants over acetic acid and formic acid catalysts at mix oxidant/different catalyst mixture. Although different catalyst were used $\left(\mathrm{CH}_{3} \mathrm{COOH}\right.$ and $\left.\mathrm{HCOOH}\right)$, so far different reduction were observed.

The results of combined oxidants $\left(\mathrm{KMnO}_{4}+\mathrm{H}_{2} \mathrm{O}_{2}\right)$ in the presence of $\mathrm{CH}_{3} \mathrm{COOH}$ and $\mathrm{HCOOH}$ catalyst in sulphur reduction. $\mathrm{CH}_{3} \mathrm{COOH}$ catalysed system gave sulphur reduction of $27.02 \%$ that is $0.8745 \mathrm{wt} \%$ reduction while the $\mathrm{HCOOH}$ catalysed system was able to reduce the sulphur to $0.3246 \mathrm{wt} \%(73.00 \%)$ reduction. This is indicated that, sulphur reduction is enhanced by strong acidic catalyst (HCOOH). [36] Otsuki et al. (2000) have reported that the sulphur content of oxidized vacuum gas oil was reduced to $0.01 \mathrm{wt} \%$ and most of benzothiophene compounds were removed by $\mathrm{H}_{2} \mathrm{O}_{2}$ /formic acid oxidation-extraction system. Although the results were comparable, so far, formic acid
$(\mathrm{HCOOH})$ catalysed reaction was slightly higher by $(44.00 \%)$ sulphur reduction where it reduce the sulphur content of heavy crude by $(73.00 \%)$ while Acetic $\left(\mathrm{CH}_{3} \mathrm{COOH}\right)$ reduce the sulphur content of heavy crude by $(27.02 \%)$. However the replicate trials showed results where formic acid $(\mathrm{HCOOH})$ catalysed reaction are consistently having higher reduction sulphur. Therefore the major difference however might be due to difference in acidity of the two catalysts and temperature. This research findings are disagreeing with [37] Amir and Payam (2015) findings of 50.90\% sulphur reduction using $\left(\mathrm{H}_{2} \mathrm{O}_{2} / \mathrm{HCOOH}\right)$ and by $49.54 \%$ sulphur reduction for $\left(\mathrm{H}_{2} \mathrm{O}_{2} / \mathrm{HCOOH}\right)$ at $60^{\circ} \mathrm{C}$. When compare with the study of [38], [39-40] (Haruna and Zubairu, 2017b), who reported sulphur reduction using $\left(\mathrm{KMnO}_{4} / \mathrm{HCOOH}\right)$ at $60^{\circ} \mathrm{C}$ and $80^{\circ} \mathrm{C}$ obtained $(48.09 \%)$ and $(49.09 \%)$. This indicated that, by using combined oxidants system at reaction temperature $60^{\circ} \mathrm{C}$ slightly increased the oxidation reaction. However there is significance difference for oxidation reaction, using $\left(\mathrm{KMnO}_{4}+\mathrm{H}_{2} \mathrm{O}_{2}\right)$ oxidant in the presence of $\mathrm{CH}_{3} \mathrm{COOH}$ and $\mathrm{HCOOH}$ catalyst mixture at constant temperature.

In comparison, combined oxidants $\left(\mathrm{KMnO}_{4}+\mathrm{H}_{2} \mathrm{O}_{2} / \mathrm{CH}_{3} \mathrm{COOH}\right)$ oxidant was found to have been better oxidation-desulphurization effect than using single oxidant $\left(\mathrm{KMnO}_{4} / \mathrm{HCOOH}\right)$. This findings differ with work reported by [5], [41], [42-43] Abdullahi et al. (2012), whose reported $78.79 \% \quad(0.318 \mathrm{wt} \%)$ reduction, using $\mathrm{H}_{2} \mathrm{O}_{2} / \mathrm{CH}_{3} \mathrm{COOH}$, at $90^{\circ} \mathrm{C}$ for 15 minutes and sulphur extracted crude oil with Heptane by $1: 2$, for oxidativedesulphurization of heavy petroleum, besides this has been more better system since it can be operate at temperature of $60^{\circ} \mathrm{C}$ which is below $90^{\circ} \mathrm{C}$.

Table 3: showed the results of sulphur reduction in the oxidized oil after extraction with Dimethylsulphoxide (DMSO), it was observed that, sulphur concentration levels in the oxidized oil after extraction is higher than that of the fresh sample, this was increased by $(252.52 \%)$ with $(2.1391 \mathrm{wt} \%)$ for sample (A) and (303.56\%) with $(3.6227 \mathrm{wt} \%)$ increased for sample (B). This happen as a results of the solvent used (DMSO), which indicated that, the solvent was found to be a poor solvent for extraction of oxidized sulphur because it introduce more sulphur into the oxidised oil. 


\section{Conclusion and Recommendation}

\subsection{Conclusion}

The study concluded that combined oxidants $\left(\mathrm{KMnO}_{4}+\mathrm{H}_{2} \mathrm{O}_{2}\right)$ with formic acid $(\mathrm{HCOOH})$ catalysed reaction system is better than using combined oxidants $\left(\mathrm{KMnO}_{4}+\mathrm{H}_{2} \mathrm{O}_{2}\right)$ with acetic $\mathrm{CH}_{3} \mathrm{COOH}$ catalyst, this is due to the high sensitivity of formic acid which gave sulphur reduction of $(74.00 \%)$ with combined oxidants $\left(\mathrm{KMnO}_{4}+\mathrm{H}_{2} \mathrm{O}_{2}\right)$. Moreover DMSO was found to be a pathetic and inadequate solvent for extraction of oxidized sulphur since, it present more sulphur into the oxidised oil higher than that up fresh sample.

\subsection{Recommendations}

It is recommended that further research is required to improve the comprehensive adeptness of this method, it also require in future research that $\left(\mathrm{KMNO}_{4} / \mathrm{HCOOH}\right)$ catalysis should be further studied at different temperatures in other to optimised oxidation desulphurization and as well as another solvents to replace DMSO should be used in the extraction process of the oxidized sulphur, in other obtained perfect extraction.

\section{References}

[1] Chunshan S. New Approaches to Deep Desulfurization for Ultra-Clean Gasoline and Diesel Fuels: An Overview. Fuel Chemistry Division Preprints. 2002; 47 (2): 438-444.

[2] Hosseini H, and Hamidi A. Sulfur Removal of Crude Oil by Ultrasound-Assisted Oxidative Method. Proceeding of International Conference on Biological, Civil and Environmental Engineering Dubai, 2014; March 17-18, Pp 2328.

[3] Desouky S, Al-sabagh A., Betiha M, Badawi A, Ghanem A, and Khalil A. Catalytic Aquathermolysis of Egyptian Heavy Crude Oil. International Journal of Chemical, Molecular, Nuclear, Materials and Metallurgical Engineering. 2013; 7 (8): 638-643.

[4] Darkhan D. Production and processing of sour crude and natural gas-challenges due to increasing stringent regulations. 2013.

[5] Abdullahi DM, Abubakar GI, Musa U, Shehu A, and Yababa NA. Comparative Study on Sulphur Reduction from Heavy Petroleum-Solvent Extraction and Microwave Irradiation Approach. 2012; 3 (6): 949-960.

[6] Hanni VD, Mustafa HD. Innovative Refining TechnologyCrude Oil Quality Improvement (COQI). Real Innovators Group, Chemical Engineering Division, Santaeruz E, Mumbai, India. 2004; 330-335.

[7] Huang D, Wang YJ, Yang LM, Luo GS. Chemical Oxidation of Dibenzothiophene with a Directly Combined Amphiphilic Catalyst for Deep Desulfurization. Industrial Engineering Chemical Research, 2006; 45: 1880.

[8] Germain M, and Herman VW. Technology Development Meet Refining Challenges. In: World Petroleum Congress.
$2003 ; 134-140$.

[9] Nicholas EL, and Rashid MK. Microwave-Promoted Desulphurization of Heavy and Sulphur-Containing Crude Oil. Energy \& Fuels. American Chemical Society. 2008; 30 (20): 40 .

[10] Gore W, Bonde S, Dolbare GE, and Skov EP. Method of Desulphurization and Dearomatization of Petroleum Liquids by Oxidation and Solvent Extraction. US patent. 2003; 6596914 B2.

[11] Haruna SY, and Zubairu AY. Oxidative Desulphurisation (ODS) of Sulphur Content in Heavy Crude Oil Using Potassium Permanganate over Formic Acid Catalyst $\left(\mathrm{KMnO}_{4} / \mathrm{HCOOH}\right)$. International Journal of Sciences \& Engineering Technology. 2017; 14 (2): 12-29.

[12] Barbara P, Rufino MN, Campos-Martin JM, and Fierro JLG. Towards near Zero-Sulphur Liquid Fuels: a Perspective Review. Catalysts Science Technology. 2011; 1: 23-42.

[13] Dysard JM, Hou Z, McConnachie JM, Malek A, Gupta R, and Lewis WE. Desulfurizing Organosulfur Hetrocycles in Feeds with Supported Sodium. U.S. Patent. 2009; 7507327, Mar 24.

[14] Hossein H, and Abdolghader H. Sulfur Removal of Crude Oil by Ultrasound-Assisted Oxidative Method. International Conference on Biological, Civil and Environmental Engineering. 2014; March 17-18, Dubai (UAE), 10-11.

[15] Speight J. The Chemistry and Technology of Petroleum. 2007; Boca Raton: Taylor \& Francis Group.

[16] Speight J. The Refinery of the Future. 2011; Oxford: Elsevier Inc.

[17] Robinson PR. (2013). Petroleum Processing Overview. Kate: Louisiana State University.

[18] Zhu W, Xu Y, Li H, Dai B, Xu H, Wang C, Chao Y, and Liu H. Photocatalytic Oxidative Desulfurization of Dibenzothiophene Catalyzed by Amorphous $\mathrm{TiO}_{2}$ in Ionic Liquid. Korean Jor Chem Eng. 2014; 31 (2): 211-217.

[19] Chen H, Zhang W, Chen J, Cai Y, and Li W. Desulfurization of various organic sulfur compounds and the mixture of DBT +4, 6-DMDBT by Mycobacterium sp. ZD-19. Bioresource Technology. 2008; 99: 3630-3634.

[20] Raja LQ, Dong LX, Linhua SQ, Mengfai L, Hamid OA and Zifeng Y. Desulphurization of Saudi Arabian Crudes by Oxidative-Extraction Method. Applied Petroleum Res. 2015; 5: 335-362.

[21] Girgis M, and Gates B. Reactivities, Reaction Networks and Kinetics in High-Pressure Catalytic Hydroprocessing. Ind. Eng. Chem., 1991; 30: 2021-2058.

[22] Ma X, Sun L, and Song C. Deep Desulfurization of Diesel Fuels by a Novel Integrated Approach." U.S. AAD Document Control Centre M/S. 2001; 921-1007.

[23] Schulz H. Walter B, Peter W, and Farid O. Gas Oil Deep Hydrodesulfurization: Refractory Compounds and Retarded Kinetics." Catalysis Today. 1999; 49: 87-97.

[24] Sami M. Chemistry of Petrochemical Processes. Second Edition, Gulf Publishing Company, Houston, Texas, 2000; 1228. 
[25] Muhammad AB. Thermal Evolution of Aliphatic and Aromatic Moieties of Asphaltenes from Coals of Different Rank: Possible Implication to the Molecular Architecture of Asphaltenes. China Journal of Geochemistry. 2015; 34 (3): $422-430$.

[26] Whitehurst DD, Farag H, Nagamatsu T, Sakanishi K, and Mochida I. Assessment of Limitations and Potentials for Improvement in Deep Desulfurization through Detailed Kinetic Analysis of Mechanistic Pathways. Catalysis Today. 1998; 45: 299.

[27] Ojinnaka CM, Osuji LC, Achugasim O. Remediation of Hydrocarbons in Crude Oil Contaminated Soils Using Fenton's Reagent. Environmental Monitoring Assessments. 2012; 184 (12): 6527-6540.

[28] Lin TB, and Huang C. Oxidative Desulphurization and Denitrogenation of Petroleum Oils, US Patent. 2007; 7276152 B2.

[29] Zapata B, Pedraza F, and Valenzuela M. Catalyst Screen for Oxidative Desulfurization using Hydrogen Peroxide. Catalysis Today. 2005; 106: 219-221.

[30] Tam P, Kittrell J. and Eldridge J. Desulfurization of Fuel Oil by Oxidation and Extraction. Enhancement of Extraction Oil Yield. Ind Eng Chem Res. 1990; 29: 321-324.

[31] Paniv P, Pyshev S, Gaivanovich V, and Lazorko O. Noncatalytic Oxidation Desulfurization of the Kerosene Cut. Chemical and Technology of Fuels and Oils. 2006; 42 (3): 159-168.

[32] Murata S, Murata K, Kidena K, and Nomura M. A Novel Oxidative Desulfurization System for Diesel Fuels with Molecular Oxygen in the Presence of Cobalt Catalysts and Aldehydes. Energy Fuels. 2004; 18 (1): 116-121.

[33] Chen L, Guo S, and Zhao D. Oxidative Desulfurization of Simulated Gasoline over Metal Oxide-Loaded Molecular Sieve. China Journal Chemical Engineering. 2007; 15 (4): 520-523.

[34] Rosa M, Lamberti M, Pellecchia C, Scettri A, Villano R., and Soriente A. An Efficient Solvent Free Catalytic Oxidation of Sulfides to Sulfoxides with Hydrogen Peroxide Catalyzed by a Binaphthyl-bridged Schiff Base Titanium Complex. Tetrahedron Letters. 2006; 47 (40): 7233-7235.
[35] Lanju C, Shaohui G, Dishun Z, Jialin W, and Tong M. Oxidation of Thiophenes over Silica Gel Using Hydrogen Peroxide and Formic Acid. Energy Sources. 2008; 30 (4): 370-376.

[36] Otsuki S, Nonaka T, Takhashima N, Quian W, Ishihara A, Imai T, and Kabe T. Oxidative Desulphurization of Light Gas Oil and Vacuum Gas Oil by Oxidation and Solvent Extraction. Energy and Fuels. 2000; 14: 1232-1239.

[37] Amir F, and Payam S. Sulfur Reduction of Heavy Crude Oil by Oxidative Desulphurization. Petroleum and Coal. 2015; 55 (3): 295-302.

[38] Haruna, SY, and Zubairu, AY. Deteriorating of Sulphur Content of Heavy Crude Oil via Oxidative Desulphurization (ODS) Using Fenton's Reagents Oxidant over Acetic Acid Catalyst. International Journal of Pure and Applied Science. 2017; 14 (1): 1-13.

[39] Huang D, Wang YJ, Cui YC, and Luo GS. Direct Synthesis of Mesoporous $\mathrm{TiO}_{2}$ and its Catalytic performance in DBT oxidative desulfurization. Microporous and Mesoporous Materials. 2008; 116: 378-385.

[40] Ahmad H, Tsafe AI, Zuru AA, Shehu RA, Atiku FA, and Itodo AU. Physicochemical and Heavy Metals Values of Nigerian Crude Oil Samples. International Journal of Natural and Applied Sciences. 2010; 6 (1): Pp 10-15.

[41] Al-Zahrani IM. Model System Desulfurization by using Liquid-Liquid Extraction and Adsorption Techniques. M. Sc Thesis, King Fahd University of Petroleum \& Minerals, Dhahran, Saudi Arabia. 2009.

[42] Bakare HO, Esan AO, and Olabemiwo OM. Characterization of Abgabu Natural Bitumen and its Fractions Using Fourier Transform Infrared Spectrometry. Chemistry and Materials Research. 2015; 7: 1-11.

[43] Noora ND. Adsorption Study of Desulfurization of Diesel Oil Using Activated Charcoal. A Thesis Presented to the Faculty of the American University of Sharjah College of Engineering in Partial Fulfillment of the Requirements for the Degree of Master of Science in Chemical Engineering Sharjah, United Arab Emirates May, 2015. 